\title{
Oficina temática agrotóxico: contribuições para o processo de ensino e aprendizagem nas ciências da natureza
}

\section{Agrotoxic theme workshop: contributions to the teaching and learning process in natural sciences \\ Oficina temática agrotóxico: contribuciones para o processo de ensino e aprendizagem nas ciências da natureza}

\author{
Jacqueline Silveira Brum (jacquebrum@gmail.com)
}

Universidade Federal do Pampa, campus Dom Pedrito.

Ana Carolina Gomes Miranda (ana.miranda@ufop.edu.br)

Universidade Federal de Ouro Preto.

Ana Carolina de Oliveira Salgueiro de Moura (anamoura@unipampa.edu.br)

Universidade Federal do Pampa, campus Dom Pedrito.

Resumo: A pesquisa desenvolvida no presente trabalho possui caráter predominantemente qualitativo. A intervenção foi realizada em uma Escola Municipal de Ensino Fundamental, em Dom Pedrito/RS, contou com vinte e um (21) estudantes do sétimo ano para participar do desenvolvimento da oficina temática agrotóxico. Dessa forma, possui como objetivo favorecer o processo de aprendizagem dos conteúdos das ciências da natureza, a partir da discussão de temas socioambientais intimamente relacionados com a realidade dos educandos investigados. Foram utilizados questionários como instrumentos para a coleta de dados e para análise dos dados coletados, utilizou-se as etapas metodológicas propostas por Bardin (1994). Diante disso, os resultados revelaram que as oficinas temáticas possuem potencial para contribuir de forma significativa na construção de conhecimentos em sala de aula.

Palavras-chave: Agrotóxico; Ciências da Natureza; Oficina Temática.

Abstract: The research developed in this work has a predominantly qualitative character. The intervention was carried out in a Municipal Elementary School, in Dom Pedrito/RS, with twenty-one (21) seventh-year students to participate in the development of the thematic workshop: "pesticides". In this way, it aims to favor the learning process of the contents of natural sciences, from the discussion of socio-environmental themes closely related to the reality of the investigated students. Questionnaires were used as instruments for data collection and to analyze the collected data, the methodological steps proposed by Bardin (1994) were used. Therefore, the results revealed that thematic workshops have the potential to significantly contribute to the construction of knowledge in the classroom.

Keywords: Pesticides; Natural Sciences; Thematic Workshop. 
Resumen: La investigación desarrollada en este trabajo tiene un carácter predominantemente cualitativo. La intervención se llevó a cabo en una Escuela Primaria Municipal, en Dom Pedrito / RS, con veintiún (21) alumnos de séptimo año para participar en el desarrollo del taller temático: "plaguicidas". De esta forma, se pretende favorecer el proceso de aprendizaje de los contenidos de las ciencias naturales, a partir de la discusión de temas socioambientales estrechamente relacionados con la realidad de los estudiantes investigados. Se utilizaron cuestionarios como instrumentos para la recolección de datos y para el análisis de los datos recolectados, se utilizaron los pasos metodológicos propuestos por Bardin (1994). Por tanto, los resultados revelaron que los talleres temáticos tienen el potencial de contribuir significativamente a la construcción del conocimiento en el aula.

Palabras-clave: Plaguicidas; Ciéncias de la naturaleza; Taller temático.

\section{INTRODUÇÃO}

As instituições de ensino desempenham um papel muito importante na vida dos indivíduos, ao promover o ensino por meio do compartilhamento de aprendizagens, por meio de diálogos e troca de experiências do seu cotidiano. Miranda et.al (2015), ressaltam a importância de trabalhar os conteúdos curriculares de forma contextualizada, relacionados com o contexto social dos educandos. Assim, os conhecimentos adquiridos pelos estudantes se tornam-se significativos e duradouros, preparando-os para que possam pensar e agir de forma a interagir e compreender o mundo.

Os documentos oficiais da educação brasileira, como o Referencial Curricular Gaúcho (2018), enfatizam a importância de trabalhar os conteúdos curriculares, afim de utilizar diferentes conhecimentos para resolver um fenômeno apresentado (social, político, cultural, ambiental, entre outros) de forma interdisciplinar e contextualizada, relativos ao contexto social dos alunos. Diante disso, o ensino de Ciências é um desafio, principalmente na busca por estratégias em que os educandos possam relacionar as aprendizagens com significados para o seu cotidiano.

Nessa perspectiva, instiga-se os estudantes para que possam (re)conhecer nos processos de aprendizagem um ensino crítico e emancipador, conforme Freire destaca (1987):

É na realidade mediatizadora, na consciência que dela tenhamos educadores e povo, que iremos buscar o conteúdo programático da educação. O momento deste buscar é o que inaugura o diálogo da educação como prática da liberdade. (FREIRE,1987, p.50). 
Foi proposto neste trabalho o desenvolvimento de práticas pedagógicas no espaço escolar, por meio de uma oficina com a temática agrotóxico, para contextualizar a realidade e o cotidiano que os educandos estariam inseridos, em uma área periférica do município próxima a propriedades agrícolas. A fim de estimular a aprendizagem que tenha significado para os estudantes, com base na especificidade do educando, buscou-se articular a temática com conhecimentos científicos. Também procurou-se envolver dimensões sociais, advindas de situações do cotidiano como elemento motivador do processo de ensino e aprendizagem.

Justifica-se a escolha da temática agrotóxico, uma vez que a economia do município em que a escola está inserida é baseada em culturas de arroz, soja e pecuária, apresentando potencial para cultivo de videiras, hortaliças e oliveiras, bem como a utilização indiscriminada de agrotóxicos. Esses aspectos corroboram para que essa temática seja relevante, pois pode contribuir de forma significativa com discussões sobre os aspectos ambientais, sociais, econômicos, científicos e tecnológicos envolvidos nessa temática. Segundo Fonseca e Lindemann (2020), esses aspectos são extremamente importantes na articulação de práticas educativas comprometidas com uma formação crítica.

Como já supracitado, a temática precisa fazer sentido aos educandos para que eles consigam pensar a respeito de um dado conhecimento no intuito de transformar sua realidade, é para isso que a educação existe, para que os estudantes saibam empregar seus conhecimentos em todos os contextos da vida (FREIRE,1987).

Diante disso, a problemática que emergiu foi: “Como a utilização da oficina temática agrotóxico corrobora para promover a construção do conhecimento nas Ciências da Natureza"?

Dessa forma, propõe-se a elaboração e desenvolvimento de uma oficina temática com o objetivo de favorecer o processo de aprendizagem dos conteúdos das ciências da natureza, a partir da discussão de temas socioambientais intimamente relacionados com a realidade dos educandos investigados.

Diante disso, elencou-se esta estratégia de ensino, desenvolvida em uma turma, das séries finais, do ensino fundamental, planejou-se criar possibilidades para problematizar situações do cotidiano, articulando com o ensino das Ciências e envolver os alunos em um processo ativo da construção do próprio conhecimento. 


\section{A IMPORTÂNCIA DO ENSINO E A TEMÁTICA SOCIOAMBIENTAL}

Um dos grandes desafios do docente é desenvolver práticas educativas que possibilitem uma leitura crítica do mundo, utilizando-se delas para estreitar o conhecimento às práticas do contexto social. Miranda, Braibante e Pazinato, (2018) intencionam a adoção de alternativas metodológicas, no intuito de que as estratégias favoreçam, por intermédio da contextualização, a construção do conhecimento em áreas das Ciências da Natureza.

Nesse sentido, a pedagogia Freireana estabelece como prática educativa a mediação a partir da realidade e interesse dos educandos, pautados no diálogo e saberes coletivos para estimular o pensamento crítico e a tomada de decisões. Isso faz com que o educar propicie a transformação da realidade e atenda às necessidades e especificidades das estruturas sociais, ou seja, ao educar, aprende-se também de forma contínua e mutável, de modo a contribuir com a reflexão na (re)construção do próprio conhecimento, permitindo que estes, sejam reconhecidos como autores da sua história e não objetos.

Conforme Marcondes (2008) evidencia que as oficinas temáticas contribuem para a busca de soluções para um problema a partir dos conhecimentos práticos e teóricos. A autora aponta que a temática pode ser explorada de forma abrangente visto que:

É importante que o aluno reconheça a importância da temática para si próprio e para o grupo social a que pertence. Dessa forma, irá dar uma significação ao seu aprendizado, já possuindo, certamente, conhecimentos com os quais vai analisar as situações que a temática apresenta (MARCONDES, 2008, p.69).

Compreende-se que o estudo de um determinado tema precisa fazer sentido aos educandos, é para isso que a educação existe, para que os estudantes saibam empregar seus conhecimentos em todos os contextos da vida. Freire (1987) destaca em sua obra, $A$ pedagogia do oprimido, que a aprendizagem precisa propiciar a (re)organização do conhecimento vinculado as experiências de vida para que a aprendizagem atenda as demandas reais e suas singularidades.

Diante disso, o professor assume um papel fundamental no planejamento de estratégias que viabilizem a compreensão não neutra dos conceitos das ciências, ou seja, o entendimento de conteúdos entrelaçados com aspectos sociais, econômicos, políticos e ambientais. É necessário que os professores possam debater e ampliar seus conhecimentos acerca da realidade escolar. Segundo Mertins et.al (2020), organizar o currículo tendo como 
ponto de partida problemas sociais pode potencializar a conscientização docente sobre a realidade com vistas à mudança social.

\section{ABORDAGEM TEÓRICO METODOLÓGICA}

\subsection{Metodologia da pesquisa}

A pesquisa desenvolvida neste trabalho possui caráter predominantemente qualitativo. Bogdan e Biklen (1994) ressaltam que este tipo de pesquisa possui como fonte direta de dados o ambiente natural, pois parte-se do pressuposto que o comportamento humano é significativamente influenciado pelo contexto em que os sujeitos estão inseridos. Neste tipo de investigação, a análise do processo da pesquisa é muito mais importante que o produto,

sendo os dados predominantemente descritivos.

As intervenções e os instrumentos de coleta de dados aplicados na escola foram elaborados a partir da temática agrotóxico.

A oficina foi desenvolvida em uma Escola Municipal de Ensino Fundamental, no município, de Dom Pedrito/RS, contou com a participação de vinte e um (21) estudantes, do sétimo ano, com faixa etária entre doze (12) e quinze (15) anos, compreendendo dois dias para o desenvolvimento da oficina, com sete (7) horas/aulas, de quarenta e cinco (45) minutos cada período.

\subsection{Metodologia de Ensino}

O tema foi selecionado pelos professores envolvidos neste trabalho a partir de questões socioambientais evidenciadas no contexto escolar. Analisou-se as características sociais, econômicas e ambientais da comunidade investigada e constatou-se que à temática agrotóxico poderia ser um tema potencializador de debates relacionados à realidade em que o educando se encontra inserido, bem como possíveis consequências da utilização dos agrotóxicos à saúde humana e ao ambiente.

No Quadro 1 apresenta-se uma síntese da oficina temática desenvolvida. A organização da oficina contemplou os pressupostos teóricos descritos por Delizoicov, Angotti e Pernambuco (2009) e foi elaborada a partir dos três momentos pedagógicos: problematização inicial, organização do conhecimento e aplicação do conhecimento.

Quadro 1 - Síntese das atividades desenvolvidas na oficina temática

\begin{tabular}{|c|l|}
\hline Momentos pedagógicos & \multicolumn{1}{|c|}{ Descrição das atividades } \\
\hline & - Aplicação doo questionário (Anexo 1). Foi aplicado um \\
Questionário diagnóstico & questionário diagnóstico com perguntas relacionadas ao tema. \\
\hline
\end{tabular}




\begin{tabular}{|c|c|}
\hline $\begin{array}{l}\text { (Anexo1). } \\
\text { Problematização Inicial }\end{array}$ & $\begin{array}{l}\text { - A problematização inicial foi desenvolvida com os alunos } \\
\text { problemática a partir da realidade socioambiental por meio de uma } \\
\text { reportagem local: } \\
\text { ( } \underline{\text { https://www.qwerty.com.br/2019/04/24/contaminacao-por- }} \\
\underline{\text { agrotoxicos-e-detectada-na-agua-de-sete-municipios-da-regiao/). }}\end{array}$ \\
\hline Organização do Conhecimento & $\begin{array}{l}\text { - Execução da oficina temática; foi utilizado o ambiente virtual de } \\
\text { aprendizagem, AVA, onde os alunos realizaram atividades } \\
\text { descritivas e de ilustração. Foram selecionados conhecimentos } \\
\text { biológicos para a integração da temática e da problematização } \\
\text { inicial, sistematicamente estudados sob a mediação da } \\
\text { pesquisadora. }\end{array}$ \\
\hline Aplicação do Conhecimento & $\begin{array}{l}\text { - Atividade prática- cromatografia em papel- separação de mistura } \\
\text { de cores, que separa conforme a característica química. Fez-se uma } \\
\text { analogia, entre o experimento e o método utilizado para os alunos } \\
\text { compreenderem, por exemplo, possibilidades de determinar a } \\
\text { presença de resíduos de agrotóxicos nos alimentos. } \\
\text { - Questionário final. }\end{array}$ \\
\hline
\end{tabular}

Fonte: Autores.

A seguir, será apresentado o desenvolvimento de cada um dos três momentos pedagógicos aplicados com os sujeitos dessa pesquisa.

\section{Problematização inicial}

A primeira etapa da oficina deu-se pela problematização na seguinte sequência: a) divisão da turma em cinco grupos; b) leitura de uma reportagem; c) discussão em grupo; d) sistematização por registros escritos.

A discussão em torno das indagações provocadas permitiu aos estudantes expressarem suas opiniões. Foi proposto à turma investigar: a utilização de agrotóxicos provoca alguma implicação socioambiental? Na sequência, foi entregue o texto de uma reportagem de um jornal local "Contaminação por agrotóxicos é detectada na água de sete municípios da região".

Com base na leitura discussões em grupo, os estudantes responderam as seguintes perguntas: 1) Que mensagem o texto transmite? 2) O que o grupo entendeu sobre os agrotóxicos ao ler o texto? Para que são utilizados? Quais consequências pode ocasionar a saúde? Por quê?

\section{Organização do conhecimento}

A segunda etapa da oficina foi realizar atividade no ambiente virtual de aprendizagem (AVA). A turma foi dividida em cinco grupos, cada grupo, recebeu um tablet com acesso à 
internet. Os estudantes realizaram leituras, debates e a sistematização das atividades no caderno, após concluírem, entregaram o material.

O (AVA) Ambiente Virtual de Aprendizagem são espaços disponíveis na internet, no site Wix. Nestes ambientes virtuais de aprendizagem pode-se usar: imagens, textos, vídeos, tirinhas, músicas, dentre outros objetos de aprendizagens, utilizados como recursos adaptados com fins de aprendizagem, que possibilitam o desenvolvimento do tema abordado. $\mathrm{O}$ acesso ao ambiente virtual de aprendizagem pelo link disponível em:

\section{https://jacquelinesbrum.wixsite.com/ava-agrotoxicos.}

Ao abrir o ambiente virtual, avista-se o título: Agrotóxicos, pesticidas ou defensivos agrícolas, de que forma eles impactam nossa saúde e o ambiente? Em cada página do AVA, há explicações detalhadas, orientando a forma de como acessar cada uma delas e como manusear os objetos de aprendizagens. As leituras, debates, resolução das atividades foram realizados em grupos e mediadas pela professora pesquisadora.

Como possível estratégia de ensino Melo (2011) evidencia que:

O computador é, hoje, um objeto que desperta grande interesse nas pessoas, principalmente no que se refere às crianças e adolescentes. Com isso, o uso de ferramentas digitais como apoio ao ensino pode passar a ser um tema de interesse geral no contexto da educação, como também um grande recurso para o ensino (MELO, 2011, p.6).

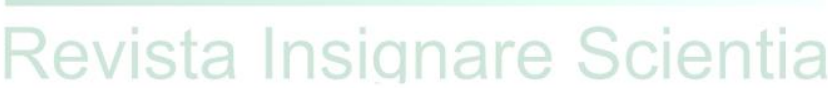

Há várias publicações que indicam estratégias diferenciadas, utilizando-se das tecnologias como ferramenta com potencial contribuição no processo do ensino e da aprendizagem. Especificamente os Ambientes Virtuais de Aprendizagens podem ser uma das possibilidades para que o docente consiga relacionar a temática em estudo com as mais diversas áreas do conhecimento. Em consonância com os argumentos supracitados, Santos (2003) destaca:

A aprendizagem mediada por AVA pode permitir que através dos recursos da digitalização várias fontes de informações e conhecimentos possam ser criadas e socializadas por meio de conteúdos apresentados de forma hipertextual, mixada, multimídia, com recursos de simulações. Além do acesso e possibilidades variadas de leituras o aprendiz que interage com o conteúdo digital poderá também se comunicar com outros sujeitos de forma síncrona e assíncrona em modalidades variadas de interatividade: um-um e um-todos comuns das mediações estruturados por suportes como os impressos, vídeo, rádio e tv; e principalmente todos-todos, própria do ciberespaço (SANTOS, 2003 p.4). 
Diante disto, a tecnologia pode ser pensada como um possível recurso a contribuir com a comunicação, informação mediada na ação docente, pois, a educação pode utilizar-se também das tecnologias para ser incorporada no trabalho do professor, como ferramenta para despertar o interesse, a participação, o desenvolvimento cognitivo, instigar a tomada de decisões, estimular o raciocínio crítico.

\section{Aplicação do conhecimento}

A terceira etapa ocorreu por meio do desenvolvimento de uma atividade experimental e aplicação do questionário final.

Foi realizada a atividade experimental com a técnica de "cromatografia em papel". Suart e Marcondes (2008) ressaltam que a experimentação deve ser um momento para discussão e (re)construção do conhecimento sobre os fenômenos químicos estudados e os conceitos que os explicam. Assim são alcançando os objetivos de uma aula experimental, a qual privilegia o desenvolvimento de habilidades cognitivas e o raciocínio lógico.

A atividade experimental possui uma função significativa no despertar de interesse pela aprendizagem em Ciências, além de introduzir a linguagem científica, também é possível estimular os educandos a observar, criar hipóteses, incentivar o senso crítico e a desenvolver a autonomia na sistematização do conhecimento.

Os estudantes foram questionados se sabiam ou imaginavam, de que forma se poderia determinar a presença de agrotóxicos em alimentos? Foi-lhes esclarecido que a cromatografia é um método físico-químico de separação de misturas e que essa separação ocorre conforme as características químicas presentes nos alimentos analisados.

Além disso, ressaltou-se que a cromatografia é uma técnica que se fundamenta no isolamento de componentes presentes em uma determinada amostra, em uma fase estacionária (FE) e uma fase móvel (FM), conforme suas propriedades. Nas análises de agrotóxicos em alimentos, isto é, análises de amostras que possuem uma mistura de vários componentes, utilizam-se para determinação de agrotóxicos a cromatografia gasosa (CG) ou a cromatografia líquida (CL) (LICHON, 1992). Na literatura encontram-se estudos (ROMERO e FRENICH, 2017) que afirmam sobre as técnicas que determinam a presença de agrotóxicos em alimentos, enaltecendo a importância do método cromatográfico para esse processo. 
Com o intuito dos alunos compreenderem os conhecimentos abstratos (separação de componentes químicos nos alimentos), utilizando-se do concreto (a visualização da decomposição de cores do experimento, ou seja, o número de componentes da mistura), usouse da analogia para fazer a relação entre ambos. Possibilitando explorar conceitos científicos vinculados a temática abordada oportunizando (re) significações na aprendizagem.

\subsection{Metodologia de análise de dados}

Durante a aplicação da presente pesquisa foram utilizados questionários como instrumentos para a coleta de dados, bem como produção textual e debates em grupos e atividade experimental. Dessa forma, os dados são descritivos, caracterizando uma pesquisa predominantemente qualitativa e foram examinados por intermédio da análise de conteúdo.

Segundo Bardin (1994), a interpretação dos dados na análise de conteúdo pode ser aplicada tanto na pesquisa qualitativa quanto na quantitativa. $\mathrm{Na}$ primeira, a informação relevante refere-se à presença ou ausência de um conjunto de características em um determinado fragmento de texto. Já na segunda, leva-se em consideração a frequência com que surgem certas características no conteúdo do texto ou fragmento.

Nesse contexto, a metodologia da análise de conteúdo é uma ferramenta, na qual permite ao pesquisador a compressão do processo de construção de significados que os sujeitos exteriorizam no discurso. Justamente, por favorecer o entendimento e a interpretação das representações do indivíduo sobre sua realidade, optou-se em trabalhar nessa pesquisa com o método da análise de conteúdo.

\section{RESULTADOS E DISCUSSÃO}

A seguir será apresentada a análise dos resultados obtidos com a turma por meio das intervenções desenvolvidas, tiveram como ponto de partida a temática agrotóxico. Os dados foram categorizados de acordo com as etapas propostas por Bardin (1994), tais como: préanálise ( $1^{\mathrm{a}}$ etapa), exploração do material ( $2^{\mathrm{a}}$ etapa) e tratamento dos dados e interpretação ( $3^{\mathrm{a}}$ etapa).

Visando compreender a percepção do conhecimento dos estudantes referentes à temática agrotóxico e aos conteúdos de Química e Biologia, o questionário investigativo foi elaborado contendo três questões sobre o tema e duas específicas (Anexo 1). 
Diante disso, foram criadas categorias especificas que servirão de suporte para análise e discussão:

- Análise da problematização inicial;

- Concepções sobre os agrotóxicos e implicações à saúde e o ambiente;

\section{- Relação entre cadeia alimentar e o agrotóxico}

\section{- Reconhecer os átomos e identificá-los na tabela periódica}

Em relação à categoria "análise da problematização inicial", analisando as respostas evidencia-se que os grupos $(\mathrm{G})$, no primeiro questionamento, extraíram informações do texto, que despertam o olhar crítico na informação sistematizada, pois descrevem as consequências à saúde. Ressalta-se que os códigos alfanuméricos (G1, G2, G5) resumem a reflexão de um grupo de estudantes, conforme exposto nos enxertos abaixo:

G1-os agrotóxicos encontrados na água de Aceguá, Dom Pedrito são venenos podem prejudicar o solo e causar doenças.

G2-aprendemos várias curiosidades, causam vários riscos de contaminação para nossa saúde trás doenças.

G-5 Que estamos bebendo água contaminada, a contaminação, isso pode causar muitas doenças, alergias.

Segundo Mortimer (2000), o ponto de partida para a construção do conhecimento é que o aluno possua ideias do senso comum, consideradas não científicas. Nesse sentido, se o aluno possuir algum conhecimento em Ciências, isto torna-se um relevante instrumento para a aprendizagem sobre os riscos, efeitos e malefícios causados pelos agrotóxicos, favorecendo ao aluno mudanças de atitudes visando o bem estar individual e coletivo. A escola deve cumprir o seu papel de problematizar dos fatos, situações e acontecimentos presentes no contexto dos alunos de modo a lhes possibilitar novas maneiras de compreender a realidade vivenciada, por meio do acesso ao saber estruturado (MALDANER e ARAÚJO, 1992).

Em relação ao segundo questionamento, referente à utilização de agrotóxicos e suas implicações, os grupos expressam:

G1-Muitas coisas que acontecem, que o agrotóxico trás doenças, poluição, animais mortos, é ruim para a saúde. 
G2-Não sabemos ninguém fala nada sobre esse assunto. Na leitura aprendemos mais e descobrimos coisas importantes que podem causar doenças e alergias.

G5 Que é muito perigoso pode causar doenças como o câncer. Não escutamos muito.

Analisando as argumentações constata-se que os estudantes não conseguem definir o que é agrotóxico. Mas, evidencia-se na escrita dos grupos que eles conseguiram perceber as implicações que o agrotóxico pode ocasionar tanto a saúde humana quanto ao ambiente, que a sua utilização não é somente para exterminar as pragas da lavoura.

Com esta atividade despertou-se o olhar crítico dos estudantes, incentivada a reflexão por intermédio do diálogo, eles compreendem os danos ocasionados ao ambiente e a saúde humana pelo uso do agrotóxico. Essa problematização inicial foi o ponto de partida para que os eles conseguissem compreender os aspectos científicos relacionados com a temática em questão. A seguir serão analisadas suas concepções antes e após a aplicação da oficina.

Para a análise das respostas, os participantes estão identificados por iniciais de letras maiúsculas, "E", a fim de preservar suas identidades.

Para a categoria "concepções sobre os agrotóxicos e implicações à saúde e o ambiente", a seguir será apresentado algumas respostas dos alunos participantes:

$$
\text { - E1- ocasiona doença. }
$$

- E 4 - o veneno pode causar intoxicação, alergia, etc.

- E 6- o agrotóxico (veneno) polui o ar e mata as aves que ao consumirem o alimento envenenado, pode causar intoxicação, falta de ar...

-E16- ocasiona se eu tiver contato com o produto, febre alta e falta de ar.

Analisando as respostas dos questionários verifica-se que os participantes utilizam do senso comum para responderem aos questionamentos. Mortimer (1992) salienta que a maioria das nossas opiniões de senso comum são práticas, diretas e autênticas. De acordo com o registro dos participantes, eles não conseguem explicar o que é agrotóxico, mas tem noção do que acontece a saúde, associam as implicações decorrentes da utilização destes com a qualidade de vida. Segundo Astolfi e Develay (2011), o ensino não pode se limitar ao fornecimento de informações, seja de Química, física ou Biologia. Para os autores, o 
importante é priorizar o processo de construção do conhecimento, pois uma verdadeira aprendizagem científica ocorre quando há transformações conceituais, duráveis, de suas preconcepções.

Após a oficina, os estudantes responderam um questionário semelhante. Os resultados permitem destacar que eles conseguiram reconhecer os problemas ocasionados ao meio ambiente e a saúde humana pela utilização dos agrotóxicos, com demonstra algumas respostas:

-E 1- escreveu que o agrotóxico fica no ambiente e nos alimentos causa muitas doenças para as pessoas.

-E 4- responde- sim, porque é um veneno tóxico que pode causar sérios danos para a saúde e para o meio ambiente.

-E 6- o agrotóxico pode causar problemas respiratórios, alergias e até câncer.

-E 21- sim, o agrotóxico pode envenenar todo o meio ambiente até as pessoas e até causar câncer.

Como mencionado, nas respostas dos participantes, há uma (re)construção de significados, evidencia-se o entendimento dos participantes E1, E6 e E21 quanto aos riscos ocasionados à saúde, ambiente e ao contexto social em que se encontram inseridos. Esses aspectos corroboram com os princípios formativos da educação problematizadora considerada por Freire (1987), cujo propósito é tornar compreensível ao aprendiz o seu papel no mundo, para que seja capaz de envolvê-lo na busca por soluções. Dessa forma, buscou-se vincular saberes científicos ao contexto da temática, propiciar reflexões e modificar sua visão de mundo.

Ainda em relação ao supracitado, segundo Bochinski (1996) é importante que a escola acompanhe as atuais transformações da sociedade, e não limite-se em formar sujeitos que somente dominem determinado conteúdo. Mas sim, que saibam pensar e refletir sobre as problemáticas relacionadas ao contexto em que estão inseridos, favorecendo a formação de sujeitos críticos e participativos.

Para a categoria "relação entre cadeia alimentar e o agrotóxico", destacam-se as inicialmente que a maioria dos estudantes possuem pouca noção em relação aos conceitos biológicos. Entretanto, percebe-se que os mesmos apresentam argumentos pouco satisfatórios sobre o assunto em questão. Em relação ao exposto Ausubel (2003) afirma que esse momento 
é o princípio para a construção e internalização do conhecimento. $\mathrm{O}$ autor afirma que a estrutura cognitiva dos estudantes no processo de aprendizagem, pode se reorganizar com vistas a aquisição de novos significados, pois a aprendizagem ocorre mediante a identificação e complementação das novas informações recebidas.

\author{
- E 8- não sei explicar \\ -E 14- não sei, mas deve contaminar sim \\ - E 15- sim, contaminam o solo e os animais, as pessoas, etc. \\ - E 20- não.
}

Após a oficina foi aplicado o pós-teste e verificou-se que a maioria das respostas demonstra que os estudantes estão em processo de significação conceitual. Dessa forma, pode-se observar que eles conseguiram transformar o conhecimento prévio, bem como expressá-los na linguagem escrita, conforme descrito a seguir:

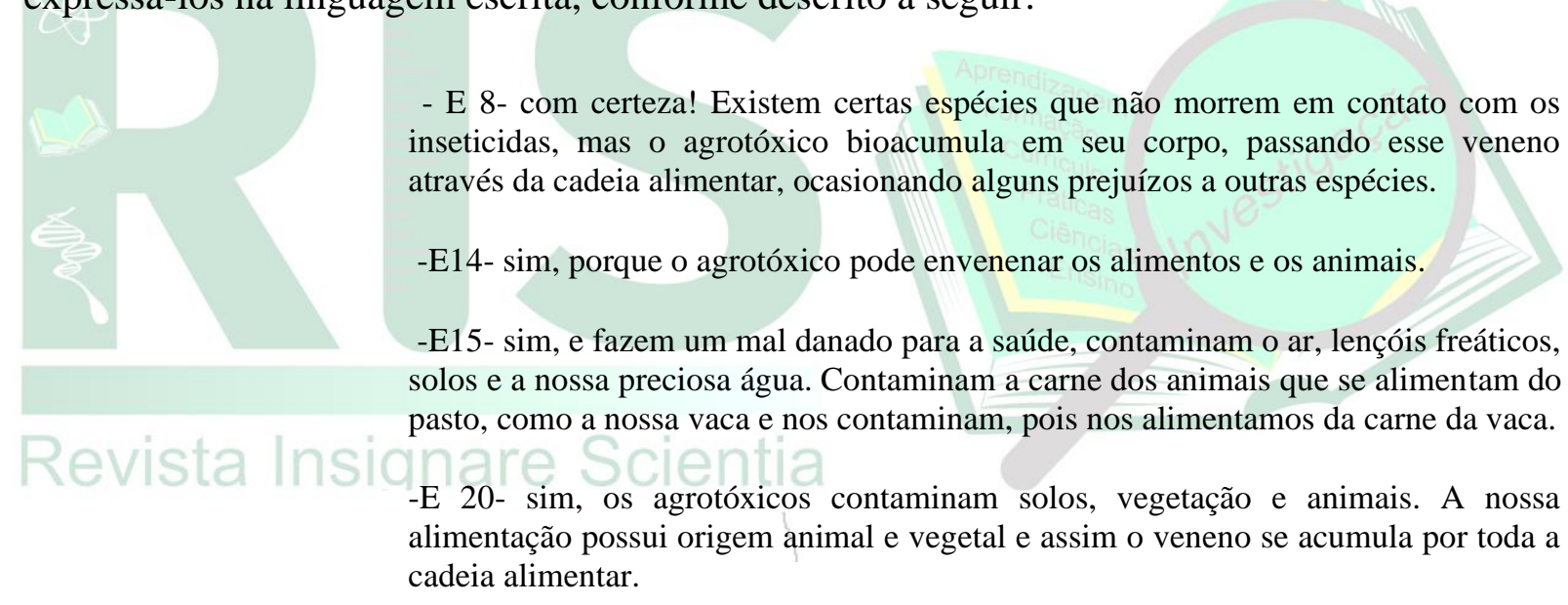

Miranda et. al (2015) alerta que uma das formas do professor preparar os estudantes para a introdução de um novo vocabulário científico está no diálogo nas aulas. O diálogo e por intermédio de problematizações entre os pares pode contribuir de forma significativa com o aprendizado. Esses aspectos corroboram com Freire (2006), ao afirmar que ao introduzir conceitos científicos nas discussões o aluno percebe a aplicabilidade do mesmo na vida real, o que pode viabilizar sua aceitação e consequentemente a aprendizagem

Para a categoria dos conhecimentos químicos, "reconhecer os átomos e identificá-los na tabela periódica" foi desafiador abordar conceitos químicos para alunos da turma do sétimo ano. Entretanto, apesar das dificuldades iniciais em relação ao desconhecimento sobre 
o conceito de átomo, após a oficina, os participantes, conseguiram identificar os átomos existentes na estrutura química dos agrotóxicos, como por exemplo do herbicida, glifosato (foi explicada à turma que a fórmula é uma forma de representar como os átomos estão organizados em moléculas, que essas moléculas são formadas por ligações químicas covalentes).

A argumentação nos questionários permitiu observar que os participantes se empenharam na construção de conhecimentos de áreas das ciências da natureza. Ao analisar os resultados obtidos na presente pesquisa, é possível inferir que os estudantes conseguiram expor argumentos, fazer inter-relações e aplicar os conteúdos científicos aprendidos. Diante disso, a utilização de metodologias diferenciadas contribui de forma significativa para o processo de aprendizagem dos conteúdos de Ciências. Cabe destacar, que desenvolver os conteúdos tendo como ponto de partida um tema que faz parte do contexto social dos educandos, favorece a reflexão e a compressão dessa realidade.

\section{CONSIDERAÇÕES FINAIS}

A partir do estudo realizado, nota-se a relevância em propiciar o debate e ampliar o conhecimento acerca dos fenômenos que ocorrem no cotidiano. Nessa perspectiva é necessário que o professor instigue a curiosidade dos educandos na busca do conhecimento por temáticas que muitas vezes, estão inseridas no dia a dia e não são abordados em aula.

O incentivo e mediação do educador é um fator extremamente relevante, o que pode influenciar de forma significativa na curiosidade e na busca por respostas por parte dos educandos. A abordagem do tema socioambiental, dá sentido as atividades propostas, pois está diretamente interligado à comunidade e, proporcionando reflexões acerca do tema.

Investigou-se como a utilização da oficina temática Agrotóxico pode favorecer o processo de ensino e aprendizagem das Ciências da Natureza. A partir dessa abordagem, foi possível aproximar os aspectos científicos relacionados à utilização de agrotóxicos e suas implicações para a saúde e qualidade de vida, evidenciando que é possível uma aprendizagem mais crítica frente ao contexto que os sujeitos estão inseridos. Segundo Torres (2010), o processo educativo deve proporcionar a formação de sujeitos crítico-transformadores, contribuindo para que os estudantes se apropriem de novos conhecimentos para atuação na sociedade. A autora afirma que o desenvolvimento da abordagem temática está em harmonia 
com os pressupostos de uma educação escolar voltada à formação e ao exercício da cidadania, com vistas à aquisição de conhecimentos e práticas voltados para construção de uma sociedade mais saudável, justa e igualitária.

Durante as intervenções, foram desenvolvidas diversas atividades, tais como: problematização de reportagens, leitura, escrita, atividades no AVA (ambiente virtual de aprendizagem) e atividade experimental, a fim de colocar o aluno no centro do processo educativo, contribuindo para a construção do seu conhecimento. Portanto, analisando os dados obtidos durante a realização dessas atividades, podemos perceber o avanço de aspectos relacionados à aprendizagem desses estudantes.

A oficina temática tem o potencial de despertar o interesse dos alunos e pode ser utilizada nas aulas de Ciências como uma ferramenta de apoio na construção de conhecimentos. E a prática experimental, uma estratégia eficaz para estimular e possibilitar a interação dos alunos com conhecimentos químicos, manifestada pela motivação dos estudantes durante a atividade. A atividade experimental procurou instigar a curiosidade dos estudantes, destacou-se como um dos pontos mais importantes, pois favoreceu o desenvolvimento de habilidades, bem como promoveu a atenção (re)significando o conhecimento dos alunos.

Por fim, é possível afirmar que o ensino de Ciências é favorecido com a utilização de temáticas que fazem parte do contexto social dos educandos e de metodologias de ensino que contribuam para a participação ativa deles no processo educativo. Acreditamos na importância deste tipo de investigação e esperamos que se torne uma prática mais presente no cotidiano das escolas, para que se dê uma real significação para o ensino.

\section{REFERÊECIAS}

ASTOLFI, J.; DEVELAY, M. A didática das ciências. Campinas: Papirus, 2011.

AUSUBEL, D. P. Aquisição e Retenção de Conhecimentos: Uma Perspectiva Cognitiva. Lisboa: Plátano, 2003.

BARDIN, I. Análise de conteúdo. Lisboa: Edições Setenta, 1994.

BOGDAN, R. C.; BIKLEN, S. K. Investigação qualitativa em educação. Tradução Maria João Alvarez, Sara Bahia dos Santos e Telmo Mourinho Baptista. Porto: Porto Editora, 1994. 
BOCHINSKI, J. B. The complete handbook of science fair projects. USA: John Wiley \& Sons, 1996.

DELIZOICOV, D.; A. J. A.; PERNAMBUCO, M. M. Ensino de Ciências Fundamentos e Métodos. $3^{\text {a }}$. ed. São Paulo: Cortez, 2009.

FONSECA, E. M.; LINDEMANN, R.H. Temática Agrotóxico na Prática Pedagógica de Professoras de Ciências: Das Compreensões às Possibilidades de Intervenção. Revista Brasileira de Pesquisa em Educação em Ciências. 20, 1307-1337, 2020.

FREIRE, P. Pedagogia do Oprimido.17.ed. Rio de Janeiro: Paz e terra,1987.

LICHON, M. J. Sample preparation for chromatographic analysis of food. J Chromatography A. 1992 .

MALDANER, O. A.; ARAÚJO, M. C. P. A participação do professor na construção do currículo escolar em ciências. Espaços da Escola, Ijuí: UNIJUI, v. 1, n. 3, 1992.

MARCONDES, M. E. R. Proposições metodológicas para o ensino de química: Oficinas Temáticas para a aprendizagem da ciência e o desenvolvimento da cidadania. Uberlandia, V.7, 2008.

MELO, D. M. B. de. Jogos digitais e objetos de aprendizagem no ensino da matemática. In: III Encontro Regional em Educação Matemática, RN, 2011.

MERTINS; S. GALLE, L. A. V.; SILVA, C. M. da. Pesquisa como princípio educativo: contribuições das perguntas dos estudantes para a aprendizagem de Química. Revista Insignare Scientia-RIS, v. 3, n. 3, p. 190 a 207, nov. 2020.

MIRANDA, A. C. G.; BRAIBANTE, M. E. F.; PAZINATO, M. S. Tema gerador como estratégia metodológica para a construção do conhecimento em química e biologia, Experiências em Ensino de Ciências V.10, No. 12015.

MIRANDA, A. C. G.; BRAIBANTE, M. E. F.; PAZINATO, M. S. Tendências do ensino e aprendizagem de forças intermoleculares a partir da análise de publicações em periódicos nacionais e internacionais. Revista Electrónica de Enseñanza de las Ciencias Vol. 17, $\mathbf{N}^{\mathbf{0}} 2$, 394-419, 2018.

ROMERO, G.; FRENICH, A. G. Applications in High Resolution Mass Spectrometry Food Safety and Pesticide Residue Analysis, 2017.

MORTIMER, E. F. Pressupostos epistemológicos para uma metodologia de ensino de química: perfil epistemológico e mudança conceitual. Química Nova, v. 15, n.3, p. 242-249, 1992.

MORTIMER, E. F. Linguagem e formação de conceitos no ensino de ciências. Belo Horizonte: Editora UFMG, 2000. 
RIO GRANDE DO SUL. Referencial Curricular Gaúcho: Educação Infantil, v. 1. Secretaria de Estado da Educação: Porto Alegre, 2018.

SANTOS. E. O. Ambientes virtuais de aprendizagem: por autorias livre, plurais e gratuitas. In: Revista FAEBA, v.12, no. 18. 2003.

SUART, R. de C.; MARCONDES, M. E. R. Atividades experimentais investigativas: habilidades cognitivas manifestadas por alunos do Ensino Médio. Em: XIV Encontro Nacional de ensino de Química, Curitiba, 2008.

TORRES, J. R. Educação ambiental crítico-transformadora e abordagem temática freireana. Tese (Doutorado em educação em Ciências). Florianópolis: UFSC, 2010.

\section{ANEXO}

Figura 1 - Questionário diagnóstico

Fonte: Autores.

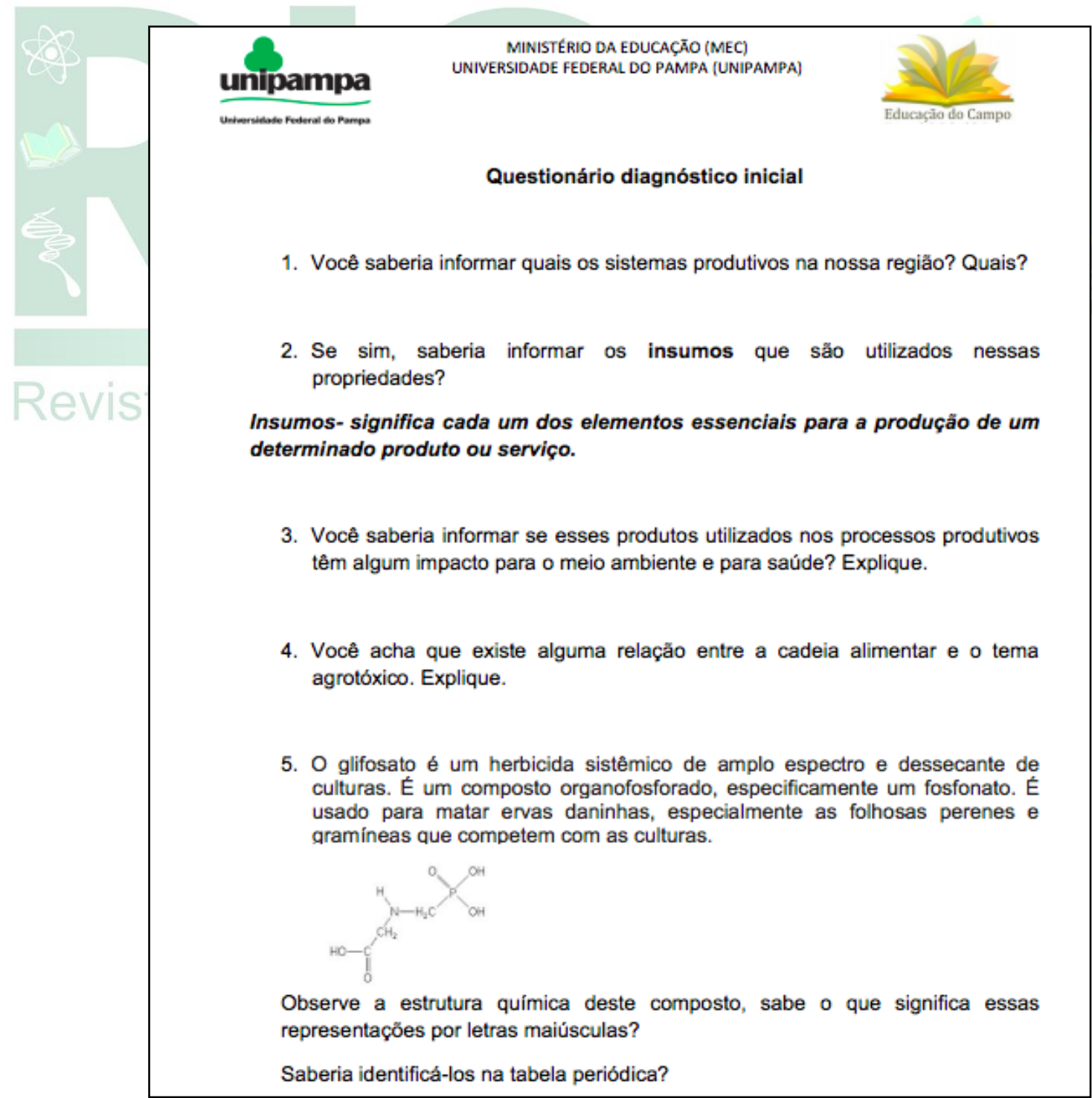

Recebido em: 23/02/2021

Aceite em: 15/08/2021 